\title{
A alteridade indígena no poema épico de Anchieta
}

\author{
JOÃO BORTOLANZA \\ Universidade Estadual de Mato Grosso do Sul \\ Universidade Federal de Mato Grosso do Sul
}

\begin{abstract}
RESUMO: No poema épico De Gestis Mendi de Saa, o Padre José de Anchieta considera os habitantes nativos do Brasil, as Brasilles gentes, como barbara gens, além de superba, crudelis, effrenis, atrox, indomita, dira e inhumana, entre outros muitos qualificativos, como justificativa para a ação catequética dos Jesuítas e para a dominação colonizadora do Governador Geral Mem de Sá. No espírito das Cruzadas, a Contra-Reforma opõe dois campos: de um lado, os católicos e civilizados europeus; de outro, os pagãos e rudes brasilíndios. Já na proposição, o poeta deixa claro seu intento: (Rex Christe), tua maxima facta / aggrediar versu memorare, ingentibus ausis: magna quibus nuper tua mittere lumina virtus / inter barberiem coepit Brasillibus oris (v. 111-114) Herói divino, Cristo Rei, age através do herói humano - magnanimum heroem Mendum (v. 164) - cujos grandes feitos consistem em eruere e Stygio Brasilles carcere mentes (v. 177). Os costumes exóticos dos indígenas, suas festas e danças, seus sacerdotes, crenças e ritos, seu modus vivendi, seu próprio habitat passam a formar um cenário, não apenas "bárbaro", mas "diabólico e infernal". Será essa demonização do índio e de seus costumes o cenário dessa primeira grande epopéia das Américas (1563), com 3135 versos vazados em Latim Clássico pelo grande Humanista Anchieta.
\end{abstract}

PALAVRAS-CHAVE: alteridade; demonização; ritual antropofágico; costumes; preconceito.

Em artigo publicado na Revista Classica (Bortolanza, 2000/2001,p. 383-92), apresentei os neologismos no poema épico de Anchieta, referentes não só aos indígenas, como a seus adereços, costumes e hábitos. E destacava que Anchieta faz parte dos que pintaram o exótico desta Terra para os europeus. O cenário para a epopéia constitui-se do mundo das trevas do paganismo, povoado por um povo infenso a leis, revelando-se embora multicor e exótico aos olhos do aedo. Será nesse campo que triunfará o braço secular-religioso do herói terreno-celeste da colonização-catequização.

Eis que o telúrico habitante da Nova Terra ganha cores a disfarçar sua nudez habitual ipsi jam picti diversicoloribus omnes incedunt pennis (vv. 1640-1641), "todos se aproximam pintados de plumagem multicolorida" -, com seus cocares elaborados por arte admirável a lhes enfeitar a cabeça - caput in speciem circumdat (facta) coronae arte laboratae mira (vv. 1644-1645) -, com exóticos estranhos "tembetás" a lhes penderem dos lábios perfurados - ex labiis pendent aut alba foratis marmora, vel virides nitido splendore lapilli 
(vv. 1646-1647). Indisfarçado encantamento com a alteridade em toda sua nudez, mas sem deixar de desvelar sua rejeição, como já deixara lavrado nos versos 339-340: Atque alios aliosque habitus per nuda dedere / membra feri, horribiles visu, vultuque minaces - "Com estes e muitos outros adereços, medonhos e feios, / cobrem os membros nus os selvagens ferozes." Horribiles visu, minaces, eis a síntese da descrição, já anteriormente assim prenunciada:

\section{Omnes vestiti patrio robusta colore membra: genas illi et frontem mediasque rubenti turparunt suras; hi nigro corpora sulco pingentes totos diversis nexibus artus, et picto veras imitantes corpore vestes' ${ }^{1}(326-330)$}

"Vestidos com as cores da tribo", com as tintas a encobrirem sua nudez, mas "enfeando, desfigurando" a face, a fronte e os membros todos. O diferente ganha roupagens européias e por isso mesmo causa estranhamento, levando a concluir pela rejeição do novo. Sequer passa pela mente do poeta o estranhamento dos indígenas face às impensadas formas de vestimentas dos recém-chegados, como entoa o contemporâneo Montaigne (1972, p. 62-5):

Não são os bárbaros motivo de maior estranheza para nós do que nós para eles (...) Não vejo nada de bárbaro ou selvagem no que dizem daqueles povos; e, na verdade, cada qual considera bárbaro o que não se pratica em sua terra. (...) Nós, conclui ele, os execedemos em toda sorte de barbaridades (Apud Suess, 1988, p. 342-3).

Volta-se o poeta para o característico de seus instrumentos, o tacape em especial, lignaque picta avium pennis (v.321) - os lenhos pintados com penas de aves - ou, como dirá mais adiante, dextera ligna gerit fabricata atque arte polita,/diversis circum pennis redimita volucrum, / queis mandenda solent confringere tempora capti ${ }^{2}$, o tacape, artisticamente fabricado e enfeitado de penas multicores, arma a marcar o caráter antropofágico do índio, sempre à espreita de presas humanas para saciar-lhe a sede cruel de sangue.

O quadro se completa com a descrição das orgias dionisíacas, homens e mulheres a embriagar-se com seus spumantia vina (v.2156), o cauim, do entardecer ao romper da aurora, princípio gerador de toda a perversidade, contundente imagem das "trevas do Tártaro" que o Herói de cruz e espada, com suas pura orientia Olympo lumina, veio dissipar (vv.129-130). O longo excerto, a ser comentado infra, (vv.1104-1135) justificase pela crueza da descrição da promiscuidade e festivas orgias majorum more, em que a

1 "Pintam os membros robustos com as cores da tribo; tingem ("enfeiam, desfiguram") com listas vermelhas as faces, a fronte e as meias pernas; o resto do corpo com riscas pretas, tão bem enlaçadas, membro por membro, que imita a pele pintada verdadeiros vestidos".

2 "A direita empunha o tacape, trabalhado com arte e polido, / ornado em derredor de penas de aves variadas: / com ele os antropófagos rompem a cabeça aos cativos". 
devassidão dos costumes se mistura aos cantos rituais da antropofagia e das bebedeiras entorpecentes dos corpos, mentes e consciências. Esse o retrato do "outro", justamente em contraponto, no momento central da vitória do Bem sobre o Mal, em que os índios da Bahia são aldeados em reduções para aí receberem as "leis" de Mem de Sá e a "moral cristã" da catequização jesuítica. Assim já dizia em carta ao Geral Diogo Laínes em julho de 1561:

Assim não existe dúvida, senão que neles se faria muito fruto, se estivessem juntos, onde se pudessem doutrinar, de que se tem experiência agora na Bahia, onde juntados em umas grandes aldeias, por ordem do governador, aprendem da melhor vontade a doutrina e rudimentos da fé, e dão muito fruto, que durará enquanto houver quem os faça viver naquela sujeição e temor (Cartas, p. 159).

O primeiro triunfo é a vitória contra o ritual antropofágico, visto aqui apenas como um hábito carnívoro e canibal (vv. 1096 a 1103):

Ergo exempta fames, et sanguinolentus edendi

Pressus amor; cupidas liquit sitis improba fauces;

Primaque cunctorum radix et causa malorum,

In laudes clarumque decus compressa cupido

Hostibus a caesis nova sumere nomina honoris.

Iam mites discunt animos gestare, manusque

Abstinuisse necis, qui nuper sanguine fuso

Gaudebant, hominum carpentes dentibus artus. ${ }^{3}$

Na visão anchietana, trata-se de uma paixão e de uma sede incontidas, sanguinolentus amor e sitis improba, de capturar inimigos para tomar-lhes os nomes, nesse rito deveras macabro para os olhos europeus, estando aí a raiz de todos os males - primaque cunctorum radix et causa malorum - costume que agora as cupidas fauces terão que abandonar, abrindo-se com isso o caminho da superação dos males.

Para verificar quão longe andava Anchieta da análise etnológica atual, baste comparar com a a seguinte análise do ritual antropofágico:

A sociedade tupinambá é antes de tudo uma sociedade de guerreiros. O guerreiro acumula mulheres, nomes e prestígio. O guerreiro morto encontra o lugar das almas e a "Terra sem Mal" que se situava no imaginário

3 "Assim se expulsou a paixão de comer carne humana, /a sede de sangue abandonou as fauces sedentas; /e a raiz primeira e causa de todos os males, /a obsessão de matar inimigos e tomarlhes os nomes,/ para glória e triunfo do vencedor, foi desterrada. /Aprendem agora a ser mansos e da mancha do crime/ afastam as mãos os que há pouco no sangue inimigo/ tripudiavam, esmagando nos dentes membros humanos". 
tupinambá tanto num horizonte geográfico-espacial, quanto em outro escatológico-espiritual. $\mathrm{O}$ guerreiro é um vingador e o vingador é o homem culturalmente completo. O guerreiro é o "santo" tupinambá, já que a vingança do inimigo permite o acesso ao paraíso. "A quebra do crânio do primeiro inimigo lhe permitirá ascender à condição plena de homem" (Suess, 1998, p. 341)4.

No segundo trecho (vv. 1104-1109), associam-se as bebedeiras e as "torpezas" da "Veneris furiosa libido": eis que viviam "feito porcos", sues ceu, chafurdando seus corpos no lodaçal, por viverem o informe, o horrível, ligando-se a "muitas", enquanto não lhes foi imposto o casamento monogâmico:

Iam quos urebat Veneris furiosa libido,

Qui coeno immersi turpissima membra iacebant,

Multarum sociata toris, informe, sues ceu,

Adsciscunt unam, quae sit mansura cubilis

Perpetui consors, vinclo sociata iugali,

Promissumque viro servet sine labe pudorem. ${ }^{5}$

Há, nesse excerto, uma forte oposição entre o antes e o depois: antes, o libidinoso, o bacanal; depois, a virtude, a consors vinclo sociata jugali. Condena-se, sataniza-se o outro, enquanto não se acultura e se transcultura.

A seqüência antropofagia, promiscuidade, bebedeiras, associada aos cantos e danças com que costumavam celebrar suas vitórias, encerra-se nestes versos (vv. 1110-1120):

Quid referam quales olim celebrare solebant

Potando cantus? quantis clamoribus auras

Replebant; quali depicti membra colore;

Quam variis avium vestiti corpora pennis?

Viderat hos croceis Aurora invecta quadrigis

Potantes, clausoque diem vesper Olympo

Componens; nox atra, poli cum trajicit alta

Culmina, et exoriens claro Venus altera caelo;

Et prius oceanis, orto iam mane secundo, Fluctibus abdiderat formosus Apollo iugales,

Abdere quam ventris cessarent gurgite vinum. ${ }^{6}$

4 A frase final é de Cunha et Castro, (1985, p. 61).

5 Há pouco a febre do impuro lhes devorava as entranhas:/ imersos no lodaçal, aí rebolavam o fétido corpo,/ preso à torpeza de muitas, à maneira de porcos/ Agora escolhem uma, companheira fiel e eterna,/ vinculada pelo laço do matrimônio sagrado/ que lhe guarda sem mancha o pudor prometido.

6 Para que lembrar os cantos que outrora entoavam/ em suas bebedeiras? os gritos com que atroavam os ares/medonhamente? as cores com que pintavam os membros?/ as penas variegadas com que enfeitavam os corpos? 
Os cantos e danças tradicionais, todo um ritual cerimonioso, a exigir "trajes a rigor", corpos pintados com as cores da tribo, ornados de penas variegadas, não passam de gritos dissonantes aos ouvidos do poeta, próprios de um ambiente comandado pelo beber desmedido. Assiste-os o pagão mundo mitológico, como marcas cronotópicas, para marcar-lhes o infindável do bacanal macabro, que carrega, a seguir, suas tintas (v. 1121-1135):

\section{Quas ibi cernere erat sordes! quam turpia visu! Quos habitus gestusque virum! Quo femina more Porrigere assuevit lasciva pocula dextra! Impletum exonerant stomachum, potata vomentes Vina; bibunt iterum pleno de ventre vomenda; Hic vomit, ille capit vomitum cratere bibitque: Indigna adspectu facies! Ibi prisca suorum Facta recensebant et turpia crimina avorum: Hic ferus incendi bellorum et sanguinis ardor; Hic fervere nova incerpendi humana cupido Membra, novis laceros tradendi nisibus artus Suppositis flammis, figendi et frusta cruentis Secta minutatim verubus, mala denique cuncta Patrandi sopitus amor iamiamque senescens His expergisci et veluti iuvenescere vinis. ${ }^{7}$}

A pintura do "outro" ganha seu clímax: bebidas, gestos e meneios impudicos, torpezas, sordidez, enquanto se preparam e se bebem as características bebidas, ao som dos cantos a rememorarem os prisca suorum facta et turpia crimina avorum - "os antigos feitos e os torpes crimes dos seus antepassados" -, enquanto se cumpria o ritual antropofágico, a celebrar a morte e glorificação do inimigo vencido. É nesse mar de sordidez, de horripilante visão, que crescem os "seus antigos e diabólicos costumes" e "enquanto assim estiverem, difícil coisa será arrancá-los do jugo de satanás, que tão senhoreados os têm". (Anchieta,

A beber, vira-os a aurora do seu róseo carro,/e a tarde ao cerrar o dia nos umbrais do horizonte!/ E a noite negra ao rolar dos altos cumes celestes/ e a nova manhã ao despertar sob a força dos raios:/ Já o belo sol, nascido neste segundo dia, engolfara/ nas ondas azuis seus corcéis, e eles ainda/ a atufar de vinho os abismos do ventre.

7 Que espetáculo de sujidões, que visão de torpezas!/ Que obscenos os gestos dos homens, que impudicos meneios/ os das mulheres que oferecem as lascivas bebidas!/ Fartam de vinho o ventre e, cheio, tudo vomitam,/ e bebem de novo e cheios aos vômitos tornam./ Um vomita, outro apanha na cuia o vómito e o bebe./ Espetáculo horrível! aí se cantavam os feitos antigos/ e as maldades criminosas dos seus antepassados,/ e feroz se erguia o terror da guerra e do sangue,/ e fervia a paixão de espedaçar corpos humanos,/ de entregá-los em postas, com renovados esforços, / à chama acesa em baixo e espetar em caniços/ os pedaços cortados em pequeninos. $\mathrm{O}$ desejo malvado/ de todos os crimes, sopitado e pouco a pouco envelhado,/ despertava e rejuvenescia ao ardor desses vinhos. 
1984, p. 175). É o que diz em conclusão desse longo excerto do poema épico: "O desejo malvado de todos os crimes (...) despertava e rejuvenescia ao sabor desses vinhos". E esse quadro das "terras da gentilidade", dos índios que "são tão bárbaros e indômitos que parecem estar mais perto da natureza das feras do que da dos homens" (Cartas, passim), que justificava a ação dos Jesuítas e a própria epopéia anchietana, como diz, em 16 de abril de 1563, ano da publicação do De Gestis, em carta a Diogo Laínes: "Para este gênero de gente, não há mesmo pregação que espada e vara de ferro, na qual, mais que em nenhuma outra, é necessário que se cumpra o compelle eos intrare", assim comentada por Viotti (1984, p. 206, n.15):

S1. 2,9 Condição prévia para a livre aceitação do Evangelho por parte dos selvagens, era seu enquadramento nas leis naturais. Com isso se fariam homens, para daí, sendo possível, se tornarem cristãos. Para enquadrá-los nesse "direito humano", nada mais indicado que a vassalagem ao Estado português oficialmente católico, chamado pela Providência a criar nesta parte do mundo uma nova sociedade civilizada.

Contraponha-se a análise antropológica de Bartomeu Melià, um jesuíta da atualidade, sem esquecer do alerta de outro jesuíta "Não se pode julgar Anchieta segundo as teorias antropológicas do século XX" (Santos, 2000, I, p. 338):

La antropofagía no se practica por sí misma, sino integrada con otros fenómenos. La antropofagía está siempre relacionada por un lado con la "venganza" y más precisamente con lo que nosotros hemos llamado la "reciprocidad negativa", y por otro, con la "fiesta", es decir la extensión y perfección de la reciprocidad positiva (...) la distribución, la más amplia que se pueda, de la carne del prisionero establece una relación de solidaridad que aleja lo más posible la frontera con el enemigo (...) los participantes son conocidos y reconocidos los unos en los otros, gracias a su nombre propio, como si tuviera que haber un parentesco de venganza (...) el prisionero es celebrado tanto o más que su vencedor. (...) “... la reciprocidad negativa y la reciprocidad positiva [son] los dos pilares de una construcción cuya clave de arco es lo sobrenatural. (...) por la carne del prisionero comulgan de la carne del espíritu y acceden a la vida eterna. (...) Prisioneros y sacrificantes comulgaban en la esencia misma de los espíritus (Melià, 2000, I, p. 210-7).

Após o longo trecho que se prende ao ritual da "alteridade", atente-se para outros aspectos do estranhamento do "novo". Os instrumentos musicais vêm descritos nos versos 411-415: são as "cabaças com canudos espetados" - curvata cucurbita inserta oblongis calamis resonantibus (411) - ou os "búzios" ou "(u)atapus", estes, dada a sua origem, são as "conchas" ou "caracóis" - cochleas sinuosas - a reboarem "horrendamente sons medonhos, cavernosos", numa visão de quem não aceita o outro, assim rematada: "tais são as trombetas desta feroz gente!". 
His edit raucos curvata cucurbita cantus, Inserta oblongis calamis resonantibus; illi Horrendum cochleas sinuosas flatibus implent, Et saevum reboant; - ea dirae classica gentis! ${ }^{8}$ (411-15)

O habitat desta barbara natio, suas ocas e tabas assim vêm designadas por Anchieta: as ocas são fumosa (v. 867), fumantia (v. 1036), atra tecta multum fumum eructantia (v. 2154) ou domos infidas (v. 2210). O que chama a atenção é a associação da oca com a fumaça, sempre pelo olhar crítico de Anchieta. Mas é o pajé um alvo contra quem Anchieta não poupa vitupérios, ele é o perverse venefice (v. 1142), enganador de crédulos, a "velha fraude" vetus fraus, cujos truques (technis - v. 1141) precisam ser desmascarados.

Numa análise minuciosa dos adjetivos empregados por Anchieta para qualificar os indígenas, assim procurava espelhar a "ideologia" do Padre Anchieta:

Farta adjetivação com o sema da "crueldade/ferocidade": os índios brasileiros são vistos como saevi, feri, crudeles, immanes, atri, cruenti, diri, atroces, feroces e sanguinolenti, tendo sido levantadas 162 ocorrências [sobre 291] (...) Cruéis duma ferocidade selvagem, muitas vezes comparada e enfocada como superior à dos lobos, leões e tigres, perigosos sobretudo para o ser humano, uma vez que este instinto sanguinário é apontado como parte do caráter indígena, os índios só poderiam mudar seus costumes se domados. É que, além desse encarniçamento, são bárbaros, hostis, indômitos e soberbos (60), infrenes em seus seus vícios, ávidos de sangue humano. Entre os adjetivos, cumpre destacar as 25 ocorrências de humanus, à primeira vista sem conotação desabonante, mas que, no texto, qualificam normalmente a antropofagia: carne (11), sangue (7), corpo ou membros (4) humanos (Bortolanza, 1998, p. 40).

Concluo com o jesuíta Paulo Suess (1998, p. 1121): "Os missionários partilham os preconceitos contemporâneos da cristandade contra a alteridade, sejam judeus, mouros, pagãos, protestantes, heréticos, índios, mestiços ou negros". É assim Anchieta ante a alteridade indígena em seu poema épico. E, ainda de acordo com Suess (1998, p. 1127), "A libertação cristã, segundo os jesuítas quinhentistas, exige dos Tupinambá aceitar a mitologia do colonizador, renunciar ao seu passado histórico e odiar sua tradição cultural." Anchieta é um homem de sua época e, como tal,

se despoja de seus laços familiares, de seus amigos conimbricenses, de uma vida religiosa tranqüila, de seu ambiente cultural e, de coração aberto se entrega ao aborígene brasílico. (...) fiel a essa causa, Anchieta irá se interessar por tudo o que diz respeito a essa nova realidade, desde o estudo

8 "Uns, da cabaça curva espetada de longos / e reboantes canudos, tiram sons cavernosos. / Outros sopram horrendamente em búzios recurvos / ecoando um som medonho: são os clarins dos selvagens." ("tais são as trombetas desta gente feroz!"). 
da língua, da geografia, da fauna e da flora, dos costumes, enfim de tudo, da vida e da morte. Ele se faz brasileiro dentro do Brasil, a partir do Brasil. É o máximo de aculturação (Santos, 2000, I, p. 339)

Seria esse o Anchieta que participou do "projeto catequético da Companhia de Jesus: uma indisfarçada desconsideração para com a identidade do outro, ao fazer dele um simulacro imperfeito e mal acabado do europeu-ele-mesmo", no dizer de Mindlin (1997, p. 47)? De qualquer forma, é esse Anchieta que fez ecoar sua voz épica em homenagem ao Governador que, sim, "resolve impor leis aos índios que vivem quais feras e refrear seus bárbaros costumes" (De Gestis, v. 906-7: saevo degentes more ferarum, frenare imposita statuebat lege), mas deixou um lastro de sangue, como descreveu Gabriel Soares de Sousa (1971, p. 132), matou muitos tupinambás, "desbaratou o gentio que vivia de redor da Bahia, a quem queimou e assolou mais de trinta aldeias, e os que escaparam de mortos ou cativos, fugiram para o sertão".

No espírito das Cruzadas, a Contra-Reforma opõe dois campos: de um lado, os católicos e civilizados europeus; de outro, os pagãos e rudes brasilíndios. Já na proposição, o poeta deixa claro seu intento: (Rex Christe), tua maxima facta/aggrediar versu memorare, ingentibus ausis: magna quibus nuper tua mittere lumina virtus / inter barberiem coepit Brasillibus oris (v. 111-114). Herói divino, Cristo Rei, age através do herói humano - magnanimum heroem Mendum (v. 164) - cujos grandes feitos consistem em eruere e Stygio Brasilles carcere mentes (v. 177). Os costumes exóticos dos indígenas, suas festas e danças, seus sacerdotes, crenças e ritos, seu modus vivendi, seu próprio habitat passam a formar um cenário, não apenas "bárbaro", mas "diabólico e infernal". É essa demonização do índio, essa satanização de seus costumes o cenário da primeira grande epopéia das Américas (1563), De Gestis Mendi de Saa, com 3135 versos vazados em Latim Clássico pelo grande Humanista Anchieta.

\section{Referências Bibliográficas}

ANCHIETA, Pe. José de. Cartas: Correspondência ativa e passiva. 2. ed. Pesquisa, introdução e notas do Pe. Hélio A.Viotti. São Paulo: Loyola, 1984.

De Gestis Mendi de Saa. Introdução, versão e notas do Pe. Armando Cardoso. São Paulo: Loyola, 1986.

BORTOLANZA, João. A ideologia da adjetivação indígena em De Gestis Mendi de Saa. In ATAS do Congresso Internacional Anchieta 400 Anos, São Paulo, 1998, p. 39-49.

. Neologismos De Gestis Mendi de Saa. In: Clássica, São Paulo, v. 13/14, n.13/14, 2000/2001, p. 383-92.

CUNHA, Manuela Carneiro da; CASTRO, Eduardo Viveiros de. Vingança e Temporalidade: os Tupinambá. In: Anuário Antropológico, 85, Rio de Janeiro (1985): 61.

MELIÀ, Bartomeu. José de Anchieta etnógrafo de la antropofagía. In Actas do Congresso Internacional "Anchieta em Coimbra - Colégio das Artes de Coimbra (1548-1998)". Porto, Fundação Eng. António de Almeida, 2000, v. I, p. 201-220. 
MINDLIN, Dulce Maria Viana. José de Anchieta: no limiar da santidade. Goiânia: Kelps, 1997.

MONTAIGNE, Michel de. Ensaios. São Paulo: Abril Cultural, 1972, p. 62-5

SANTOS, César Augusto dos. Anchieta e a Cultura Indígena. In: Actas do Congresso Internacional "Anchieta em Coimbra - Colégio das Artes de Coimbra (1548-1998)". Porto, Fundação Eng. António de Almeida, 2000, v. I, p. 325-39.

SOUSA, Gabriel Soares de. Tratado descritivo do Brasil em 1587. São Paulo: Nacional / Edusp, 1971, cap. V, p. 132.

SUESS, Paulo. José de Anchieta - Enigma e paradigma frente à alteridade Tupinambá. In: Actas do Congresso Internacional "Anchieta em Coimbra - Colégio das Artes de Coimbra (1548-1998)”. Porto, Fundação Eng. António de Almeida, 2000, v. III, p. 1119-32.

. José de Anchieta e a alteridade tupinambá. In ATAS do Congresso Internacional Anchieta 400 Anos, São Paulo, 1998, p. 337-47.

BORTOLANZA, João. L'alterité indigène dans le poème épique d'Anchieta. Classica, São Paulo, v. $15 / 16$, n. $15 / 16$, p. 249-257, 2002/2003.

RÉSUMÉ: Dans le poème épique De Gestis Mendi de Saa, le Père Joseph de Anchieta considère les habitants naïfs du Brésil, les Brasilles gentes, comme barbara gens, outre superba, crudelis, effrenis, atrox, indomita, dira et inhumana, parmi des autres qualificatifs, pour justifier l'action catéchistique des Jésuites et la domination colonisatrice du Gouverneur Géneral Mem de Sá. Dans l'esprit des Croisades, la Contre-Réforme oppose deux champs: d'un côté, les catholiques et les civilisés européens, de l'autre, les païens et rudes indigènes brésiliens. Déjà dans la proposition, le poète annonce son but: (Rex Christe), tua maxima facta / aggrediar versu memorare, ingentibus ausis: magna quibus nuper tua mittere lumina virtus / inter barberiem coepit Brasillibus oris (v. 111-114) Héros divin, le Roi Christ actue au milieu de son héros humain - magnanimum heroem Mendum (v. 164) - dont les grands faits sont constitués par eruere $e$ Stygio Brasilles carcere mentes (v. 177). Les coûtumes exotiques des indigènes, leurs fêtes et danses, leurs prêtres, croyances et rites, leur modus vivendi, leur habitat passent à construire un portrait, non seulement "barbare", mais "diabolique et infernal". Ce sera cette démonisation de l'indigène et de ses moeurs le décor pour son poème épique, le premier des Amériques (1563), avec ses 3135 vers écrits en Latin Classique par le grand Humaniste Anchieta.

MOTS-CLÉS: Altérité; démonisation; rituel anthropophage; coûtumes; préjugé. 